\title{
From the sage on the stage to what exactly? Description and the place of the moderator in co-operative and collaborative learning
}

\author{
Chris Jones \\ CSALT, Lancaster University, email: c.r.jones@lancaster.ac.uk
}

This paper reports a significant finding from a two-year study of computer conferencing used to deliver a course unit at a UK university. Computer conferencing has been applied to education alongside a concern to develop co-operative and collaborative learning strategies. The technology of computer conferencing has been identified as especially appropriate to a co-operative style of work. This study found that far from collaboration being an outcome of the deployment of computer conferencing it became in some sense the problem. A common 'gloss' on the educational changes that are taking place, with the introduction of new technologies for teaching and learning, is that the 'sage on the stage' is being replaced by 'the guide on the side'. This paper argues that this opposition rests on little substantial evidence or research. The moderator/facilitator role advocated as suitable for computer conferencing is shown to be deeply embedded in wider social actions. The orientations of the tutor are heavily inclined towards the demands of assessment. Successful computer-supported collaborative learning (CSCL) is the outcome of the co-operative work of all the members of the conference. The application of CSCL relies upon timely interventions by the tutor.

\section{A collaborative technology?}

In a standard text on open and distance learning, computer conferencing appears with advantages and disadvantages that rely on the capacity of the conference to 'facilitate' students and staff working together (Mason, 1994). Co-operation or collaboration are seen as unproblematic outcomes of the use of the computer conference. Hiltz noted that collaboration is both technically facilitated and becomes a moral requirement that involves a respecification of the teacher's role (Hiltz and Benbunan-Fich, 1997, p. 1). The outlook that associates collaborative learning with computer conferencing can be found throughout a wide range of literature (Mason and Kaye, 1989; Harasim, 1990; Kaye, 1992; McConnell, 1994; Harasim et al., 1995; O'Malley, 1995; Jonassen, 1996). 
In some educational literature co-operation and collaboration are treated as distinct approaches (Topping, 1992). In this paper they are treated as interchangeable, an approach justified by the indistinguishable definitions provided by many authors - see for example McConnell (1994); O'Malley (1995). Co-operative or collaborative learning is understood to mean learning that takes place with students and tutors working together on academic tasks. It is argued to be fundamentally different from the direct transfer of knowledge by a largely one-way transmission, the 'transmissive' model (Harasim, 1990; Hiltz and Benbunan-Fich, 1997). The terms are glossed over so as to provide an image of a movement from the 'sage on the stage' to the 'guide on the side'. It can only be noted in passing that the transmissive model contains many elements of co-operation and collaboration (Macbeth, 1990).

\section{Moderator}

Two recent texts illustrate the new role promoted for teachers associated with CMCs and computer conferencing. Jonassen comments:

Your role as the teacher must change from purveyor of knowledge to instigator, promoter, coach, helper, model and guide of knowledge construction. (Jonassen, 1996, p. 261)

Mason draws a comparison with other media:

The role of the computer conferencing teacher is the farthest removed from that of the traditional lecturer ... During the course ... the teacher's role is definitely one of facilitator and host rather than one of content provider and star of the show. (Mason, 1994, p. 42)

The two accounts converge on a style of teaching that emphasizes social skills and reduces the emphasis on content and personal delivery. The delineation of the moderator/facilitator's function has been a recurrent feature of writing and research on computer conferencing (Kerr, 1986; Feenberg, 1989; Mason, 1991). Mason comments that:

The idea of the expert teacher must give way to a network of supports and resources in which everyone has some kind of expertise to be tapped. (Mason, 1994, p. 47)

This paper explores empirically the practice of a tutor orientated toward providing a moderating role with a view to examining the claim that computer conferencing leads to the adoption of a facilitator/moderator role.

\section{The background to the research}

The research was undertaken at Manchester Metropolitan University between 1994 and 1996. The course unit, 'Technology in Communications', was part of the BA in Information Technology and Society Degree (BAITS). The unit was taught online using the FirstClass computer conferencing system.

Within the constraints imposed by the availability of technology, the communications technologies under investigation will be used to deliver the course. Material will be sent either to student's own machines or to machines made available in the lab. This 'online' approach will be supported by face to face meetings.

(BA Information Technology in Society Student Handbook 1994 supplement)

The online nature of the course was accompanied by an expectation that work would be done co-operatively in small groups without lectures. 


\section{Methodology}

An ethnographic methodology was employed to generate an adequate description of 'just what' happened when university education was transposed from a traditional setting into the new technology. Within education the qualitative approach to research is well represented, in particular the ethnographic tradition (Hammersley, 1986 a,b; Fetterman, 1984, 1986; Eastmond, 1995). The aim is to understand the setting from the point of view of those involved in it. Ethnography is an intrinsically descriptive task that resists formalization. The methods used are 'naturalistic' in the sense that they rely on the study of people and their activities in their natural environment (Fetterman, 1998). The form of ethnography adopted has been heavily influenced by work in CSCW (Computer Supported Co-operative Work) and ethnomethodology (Suchman, 1987; Heath and Luff, 1992; Hughes et al., 1993).

\section{Findings}

This paper will examine the work undertaken by the tutor who was responsible for both the course design and delivery. Within the conferencing system the tutor had the 'Moderator' role. The moderator in FirstClass is the person in charge of a specific conference, determining who can contribute and setting levels of access, in contrast to the 'Administrator' who has control of the conferencing system as a whole. The educational role of the tutor, in organizing the course, determining the content and arranging assessment, was combined with an organizational role built into the software.

\section{Course design}

Prior to the course, the tutor had identified a potential problem of the course having 'weaker' structures online.

Students are given responsibility to do the work, what happens if they don't work? therefore deadlines - therefore a schedule of tasks, readings for example, log on, send a message etc. (Interview course tutor 10/94)

Continuous assessment and deadlines set throughout the course were devised as prompts to encourage the students both to work and to work online. A surprising omission from the original course documentation was any developed idea of collaborative working. In the first weeks of the course students were given handouts explaining course features. These notes implied a form of group collaboration but there was little explicit acknowledgement of this element. The course documentation placed little emphasis on collaborative and co-operative working. The emphasis was on the 'flexibility' available for students in terms of when work might be done, and the opportunity for synthesis and reflection. In contrast the expectation of collaboration was clearly expressed at the first face-to-face meeting.

The course outline provided the mechanism for an anticipatory account of the course. It was through the production of this documentation that the tutor was accountable to the students and wider institution for the content and teaching methods of the course. It is through the detailed control of what work is to be done and how that work is done that the tutor uses the resource he/ she has provided in the course documentation and planning. The following two examples explore how the collaborative nature of the course emerged and how the assessment procedure developed. 


\section{Collaboration}

... well let me just emphasise a number of points, computer conferencing is a collaborative activity you have to work together, you don't just go off and work alone; you have to work together through the conferencing system.

(tutor introducing course unit 10/94)

The tutor made extensive comments on the process of the work done and gave advice for future work. The first part of one message is included in Table 1.

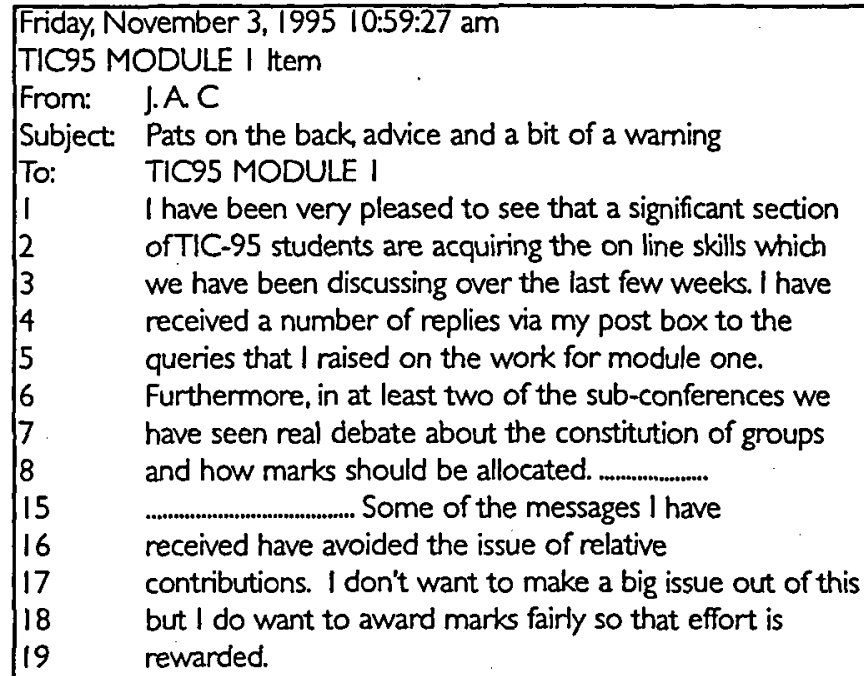

Table I: An example of tutor advice and comments.

The tutor clearly puts a great emphasis on the process of collaboration and use of the system (lines 1-8). Equally emphasis is placed upon allocating marks to individuals so that 'effort' is rewarded (lines 18-19). This concentration on how the work was done inverted the intention to stress the content of the course not the 'system' or the method of work. It would seem that the day-to-day concerns of the tutor outweighed the original design consideration that the content of the course should not be submerged by the mechanism of delivery. It was seen by the tutor as a diversion from the work he intended.

\section{Assessment}

The question of individual marks illustrates a further tension within the structure of the course. Working together and online activity were stressed by the tutor, but marks were allocated individually. The tutor wanted students to collaborate and provide information in a way that students believed would undermine group coherence. Within many educational environments marks are allocated individually and students are graded separately, so there is a tension between the pressure of assessment and the demands of group work.

The tutor's comments throughout the course show him to be concerned with academic standards, a defender of course quality. Sections of an extensive message to all students are reproduced in Table 2 . 
\begin{tabular}{|ll|}
\hline 5 & First and foremost the mark for a particular group has been \\
6 & determined by the quality of the piece submitted. I have looked \\
7 & for originality, evidence of research into the topic and the \\
8 & degree to which the question set has been answered. \\
9 & Secondly I have looked at the way in which group members \\
10 & have worked together in constructing the answer and the \\
11 & efficiency with which material coming from different individuals \\
12 & has been put together into a coherent whole. \\
(Tutor to Module $223 / 1 / 96)$
\end{tabular}

Table 2: Academic standards.

The tutor began by setting out standard marking criteria. Later a plea was made for analysis 'which goes beyond description' dealing with abstract and conceptual issues. The tutor was advising students on how to do academic work and also how to talk about it. The tutor ends by advising students to read two sub-conferences as examples of good practice (Table 3).

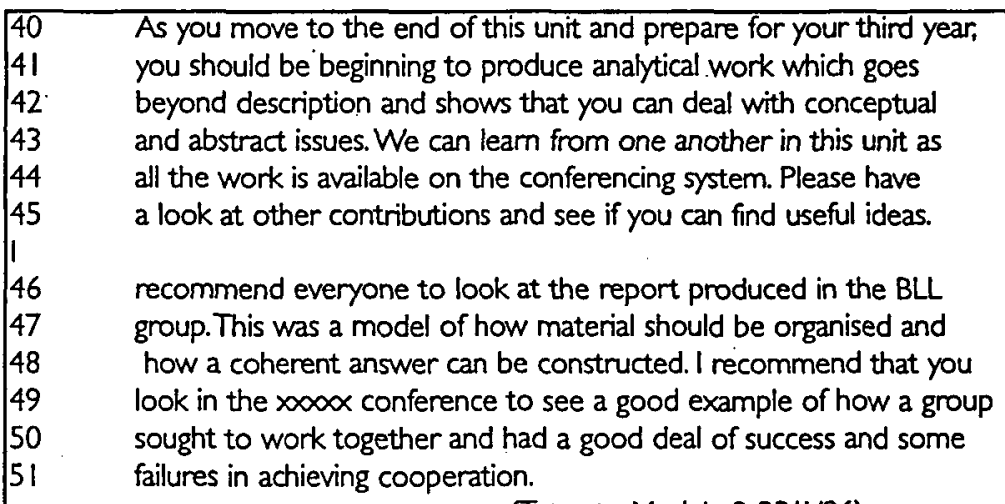

(Tutor to Module 2 23///96)

Table 3: Tutor direction and advice.

There were two related standards being applied, a common academic standard of intellectual discourse and a more specific injunction as to how to work within the conferencing system. This displays an orientation in the conference through which the tutor is encouraging the social process of doing conferencing as well as providing academic guidance. The names of the two sub-conferences were garbled in the original message, possibly as the message was translated between word-processing packages. No one notified the tutor about this. I can only assume that no student followed the academic advice and tried to learn from the model sub-conferences. The request for students to 'learn from one another' fell on deaf ears.

\section{An exceptional case}

There were several students who found group work difficult. One of these students, Ben, produced work alone, which presented the tutor with a difficult assessment problem. In November 1995 the tutor sent a message clearly setting out his requirements: 
No work will be accepted from individuals in module 2 and this means that anyone not joining a group is effectively opting out of this course unit. (tutor 7/11/95)

Despite these clear guidelines he received a submission from a lone student and faced a number of students who were clearly not co-operating.

Now my dilemma is what I should do about this ... I want them to work together. The other problem is the anomalies, Ben's a complete anomaly ... Ben's produced a good piece of work but he cannot work with others, so what sort of moderation can you bring in about being unable to work with others, ... (Field Notes 16/1/96)

Ben was clearly thought by the tutor to be of an exemplary academic or intellectual level, his submission was identified as a model showing the required academic standard.

From 12 February Ben sent one message a week asking for collaborators and suggesting possible topics. On 18 March Ben announced;

I plan to work alone on a project as it looks as if there is little interest in collaboration from others in the unit. I have not finalised the subject area as yet... (Ben to TIC95 Projects 18/3/95)

This message was followed by another in Projects on 22 March. It was not until 16 April that Ben asked for a sub-conference to work in. 'Roadrunner' was set up reflecting a declared interest in the link between road protesters and new technology. No messages were posted to the conference apart from the course tutor until 2 May 1996:

no road project following a problem finding a focus . . . attached is my digital audio broadcasting project submission. (Ben to 'Roadrunner' 2/5/96)

The tutor had begun with a rule that groups should have a maximum of five and a minimum of three members. At the end of the unit he had a conference with a lone member who had not posted to the conference and had changed his subject without notification.

On 7 May the tutor commented:

Then there is the problem of Ben. Last time I looked there was only my letter in the conference and he has changed his subject at the last minute; there is a real problem here. Do I mark him for non-co-operation? (Field Notes 7/5/96)

When the marking had been completed I discussed assessment again and was told:

Ben's was the best but he didn't collaborate. I've penalized him for working on his own. If I was blunt I would say it was mainly his fault ... effectively he refused to collaborate. So his work is reduced from 70 to 65 per cent, because a percentage of the mark was for collaboration the mark for the project was less than the content. Let me be clear it was a notional reduction. I mean, how do you decide on the reduction? (Field Notes 18/6/96)

The tutor had posted marks to all the sub-conferences explaining the marking scheme for the project and a separate message reminding groups of the overall weighting that gave projects 50 per cent of the course mark (Table 4).

Within the marks massaging the 'notional' reduction for Ben takes on a formal appearance because a definite proportion of the marks, 30 per cent, is identified as being awarded for the way the work was produced. 


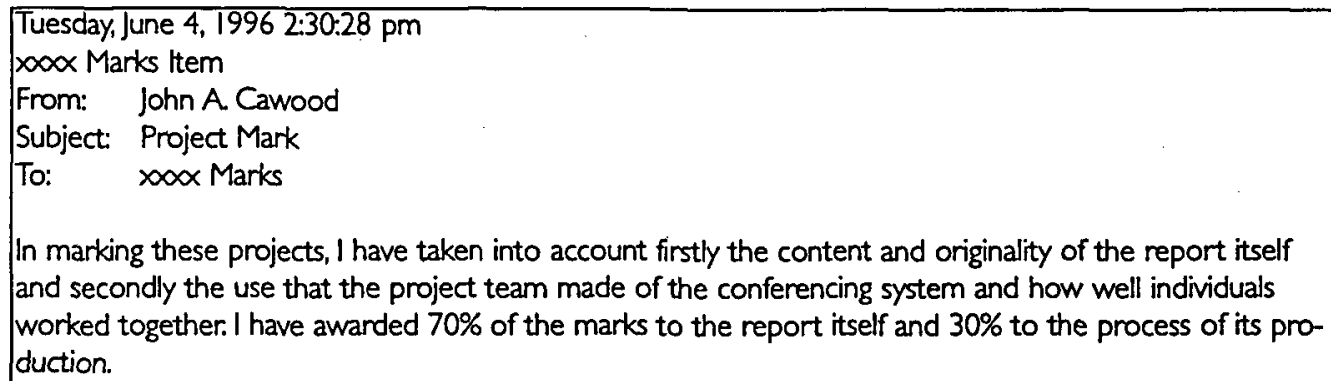

Table 4: Project mark

Ben's case casts light on the way in which definite course aims are subject to the working out of the contingencies of the course's development. The 'plan' for all students to be in groups is repeatedly unrealized and the tutor has to make ad hoc day-to-day decisions about whether to allow the situation to continue and then how to assess a student that is so clearly in breach of expressed course criteria.

\section{Discussion and conclusions}

The nature of collaborative effort was orientated towards the expectations implicitly and explicitly embedded in the course structure. The original course design mentioned little about collaboration but was clearly designed around groups achieving the completion of a series of modules. The tutor's initial comments raised the profile of collaborative working as a key component of the course. How these features of the course were achieved was then subject to ad hoc and mundane interventions. Collaboration was not something that could be pre-planned, either by good software design or by the pedagogic design of the course unit. It relied upon in situ day-to-day management of the conference.

This conclusion echoes some debate within the CSCW community about the status of plans (Bardram, 1997). Collaboration as planned action has an ironic status, in that the members of the conference first must work together, collaborating in order to produce the context for their joint activity. The scheme for collaboration is a resource for the work rather than in any real sense determining its course. The assessment criteria clearly did not provide clear and definite instructions for dealing with Ben's case: A range of contingent and situational factors was brought to bear, including the student's wider status as a 'good' student. The tutor had to decide if and how he could penalize this student for his failure to co-operate. The practical implication of this observation is that the timely interventions of the tutor were a significant feature enabling the plan of collaboration and accredited academic success to be achieved.

The institutional position of the tutor is exhibited in the production and use of the course aims and objectives. The tutor controls the definition of what counts as success within the conference. Assessment confirms that the tutor is in the position of holding specialist and superior knowledge. Despite the equation of computer conferencing with collaborative learning and the shift from 'knowledge-giver' to facilitator, the wider educational context remains one of assessment and accreditation. The tutor is the first line of that institutional system of accreditation of knowledge, determining what counts and how much is enough. 
There is of course a second sense in which the tutor remains in command of superior knowledge despite no longer 'delivering' lectures. The tutors are likely to know the answers to the questions they have set. Despite the emphasis on students as a resource, and on collaborative and group learning techniques, the tutor has a responsibility to 'know' the subject area. Even when relying on the students' own experience, the arbiter of the validity of these experiences remains the tutor, who is assumed to have a superior subject knowledge to the student. The tutor thus remains in command of superior knowledge despite no longer 'delivering' lectures.

The moderator's role was superficially a more social and organizational role than that provided for in the 'transmissive' approach. However, it is clear that the tutor is orientated towards marking and assessment criteria that are deeply embedded in the wider institutional arrangements of the university. The 'technology of accountability' within the educational setting ensures that the tutor remains in possession of superior knowledge (Suchman, 1993). In so far as the tutor becomes a guide it is still unclear whether they have to remain with the sage up on the stage. The tutor had hoped that the computer conferencing system would assist him in being able both to give a group mark and judge individual contributions. This was never achieved but the tutor used his plan to accomplish the marking consistently in the form of an individual allocation of marks. The plan for assessment was unwaveringly inadequate to guide the tutor without respecification of its terms to deal with the variety of ways in which students orientated themselves to the course objectives. In this way the plan had a reciprocal relationship with activity; the plan was itself made intelligible by the actions and in turn made those actions intelligible.

1. Collaboration was a moral imperative not technologically determined in any strong or weak sense.

2. The role of the tutor as moderator could be said to be constitutive of collaboration rather than an outcome of the pedagogy and technology.

3. The observations show how the ad hoc and day-to-day interventions of the tutor are orientated around the requirements of assessment.

\section{Acknowledgement}

The research for this article was conducted at the Department of Information and Communications and the Department of Sociology at Manchester Metropolitan University, United Kingdom.

\section{References}

Bardram, J. E. (1997), 'Plans as situated action: an activity theory approach to workflow systems', in Hughes, J. A., Prinz, W., Rodden, T., and Kjeld, S. (eds.), ESCW'97: Proceedings of the Fifth European Conference on Computer Supported Cooperative Work, Dordrecht: Kluwer Academic Publishing.

Eastmond, D. V. (1995), Alone but Together: Adult Distance Study through Computer Conferencing, Cresskill, N.J.: Hampton Press, Inc.

Feenberg, A. (1989), 'The written world: on the theory and practice of computer conferencing', in Mason, R. and Kaye, A. (eds.), Mindweave: Communication Computers and Distance Education, Oxford: Pergamon. 
Fetterman, D. M. (1984), Ethnography in Educational Evaluation, Beverly Hills, CA: Sage.

Fetterman, D. M., and Pitman, M. A. (eds.) (1986), Educational Evaluation: Ethnography in Theory, Practice and Politics, Beverly Hills, CA: Sage.

Fetterman, D. M. (1998), Ethnography Step by Step (2nd edn), Applied Social Research Methods Series Volume 17, Newbury Park: Sage.

Hammersley, M. (ed.) (1986a), Controversies in Classroom Research, Milton Keynes: Open University Press.

Hammersley, M. (ed.) (1986b), Case Studies in Classroom Research, Milton Keynes: Open University Press.

Harasim, L. (ed.) (1990), Online Education: Perspectives on a New Environment, New York: Praeger.

Harasim, L., Hiltz, S. R., Teles, L. and Turoff, M. (1995), Learning Networks: A Field Guide to Teaching and Learning Online, Cambridge, MA: MIT Press.

Heath, C. C., and Luff, P. (1992), 'Collaboration and control: crisis management and multimedia technology in London underground line control rooms', CSCW Joumal, 1 (1-2), 69-94.

Hiltz, S. R., and Benbunan-Fich, R. (1997), 'Supporting collaborative learning in asynchronous learning networks', UNESCO/Open University International Colloquium: Virtual Learning Environments and the Role of the Teacher, Milton Keynes, Open University, http://eies.njit. edu/ roxannel.

Hughes, J. A., Somerville, I., Bentley, R. and Randall, D. (1993), 'Designing with ethnography: making work visible', Interacting with Computers, 5 (2), 239-53.

Jonassen, D. H. (1996), Computers in the Classroom: Mindtools for Critical Thinking, Englewood Cliffs, NJ: Merrill, Prentice Hall.

Kaye, A. R. (ed.) (1992), 'Collaborative learning through computer conferencing: the Najdeen Papers', NATO ASI Series F, Berlin: Springer-Verlag.

Kerr, E. (1986), 'Electronic leadership: a guide to moderating on-line conferences', IEEE Transactions on Professional Communications, PC, 29 (1), 12-18.

Macbeth, D. H. (1990), 'Classroom order as practical action: the making and un-making of a quiet reproach', British Journal of Sociology of Education, 11 (2), 189-214.

Mason, R. (1991), 'Moderating educational conferencing', DEOSNEWS, 1(1).

Mason, R. (1994), Using Communications Media in Open and Flexible Learning, London: Kogan Page.

Mason, R., and Kaye, A. (ed.) (1989), Mindweave: Communication, Computers and Distance Education, Oxford: Pergamon.

McConnell, D. (1994), Implementing Computer Supported Cooperative Leaming, London: Kogan Page.

O'Malley, C. (ed.) (1995), Computer supported collaborative learning, Berlin: Springer-Verlag. 
Suchman, L. (1987), Plans and Situated Actions: The Problem of Human-machine Communication, Cambridge: Cambridge University Press.

Suchman, L. (1993), 'Technologies of accountability: on lizards and airplanes', in G. Button (ed.), Technology in Working Order, London: Routledge.

Topping, K. (1992), 'Cooperative learning and peer tutoring: an overview', The Psychologist: Bulletin of the British Psychological Society, 5, 151-61. 